\title{
RESTENOSIS OF THE MITRAL VALVE
}

\author{
BY \\ J. R. BELCHER \\ From the London Chest and Middlesex Hospitals
}

Received May 20, 1957

Does restenosis of the mitral valve occur? Glover (1955) says categorically that it does not. A critical survey of published cases suggests that if restenosis is defined as refusion of the commissures after their complete separation, then it is rare. Generally the original operation was inadequate, and in fact there is no case recorded in which restenosis occurred after complete division of the commissures. On the other hand, if the definition of restenosis is extended to include all cases in which the valve orifice has become smaller after dilatation or partial division, then the entity is not uncommon.

When valvotomy has been inadequate, that is where the separation of the commissures has not been carried beyond the critical area of tendon insertion (Brock, 1952), temporary and often considerable improvement in the patient's symptoms has been achieved. Even a small increase in the size of the mitral orifice may lead to a disproportionately large increase in the exercise tolerance. This amelioration has often been short-lived, because the raw edges of the cusps remain close to each other in all phases of the cardiac cycle and are hence liable to become readherent.

The refusion of completely opened commissures is a different problem. As the cusp edges can become widely separated during ventricular filling, particularly if the chordæ tendineæ are not matted together (Cooley, 1951), there may be a long interval before the restenosis develops. Possibly the only cause of readherence is a recrudescence of the rheumatic process: this suggestion is supported by the fact that in the few cases of this type reported, a history of reactivation has been given in five (McKusick, 1955; Glenn, 1956; Donzelot et al., 1953; Dussailant, 1954; and Morino, 1955). In the four cases in this series there was a history of sub-acute bacterial endocarditis in one.

As the pathology of the two varieties of recurrence of mitral stenosis is different, confusion may be avoided if they are called "true" and "false" restenosis. True restenosis will be used to refer to that which occurs after one or both commissures have been completely opened; and false restenosis, to that which occurs where neither commissure has been divided beyond the area of insertion of the papillary muscles.

\section{INCIDENCE}

At the Henry Ford symposium (Lam, 1955) the problem of restenosis was discussed, but despite the large experience of the speakers few cases were described. Brock reported four cases in a series of 350, Keyes had one in 180, and Harken said he had had 10 in 800 patients. Few details were given, but Harken said that 9 of his 10 patients had had inadequate division of the commissures originally.

Baker et al. (1955) in an analysis of 45 patients who had been followed for more than three years, found that 15 per cent deteriorated after an initial improvement, but did not refer specifically to restenosis. Glover (1955) found no evidence of restenosis in 41 of 50 patients living five years after operation. Sellors et al. (1953) did not mention the condition in their analysis of 111 cases, nor did Goodwin et al. (1955), although they did describe a patient who died 15 months after operation and who was found to have a tightly stenosed and calcified valve. Turner and Fraser 
(1956) refer to four cases of restenosis in a series of 250 , but in each of these the original valvotomy was inadequate. Wood (1956) has said that true restenosis occurs in 2 per cent per year of patients subjected to valvotomy, but he makes the point that as the natural history of mitral valve disease spreads over a period of fifteen years, the true incidence of restenosis will not be known for some years to come Wood (1954).

The evidence for restenosis in the reported cases has been based either on post-mortem findings or on examination of the valve at a second operation (Table I). Some authors in searching for evidence of restenosis have found none (Glover, 1955, and Muller, 1952). Yet others have described cases where the evidence was based on reappearance of the diastolic murmur (Canigia, 1955) or where the stenosis was found to be at the level of the chordæ tendineæ (Jordan, and Hellems, 1952). These have not been included in the table as the evidence was not thought to be strong enough to call them examples of restenosis. It will be seen that few cases of true restenosis have been described: there is no case in which both commissures were fully split.

TABLE I

Summary OF THE RePorted CASES OF RESTENOSIS

\begin{tabular}{|c|c|c|c|c|c|}
\hline Author & Age & Sex & Reoperation or necropsy & Type & Comment \\
\hline 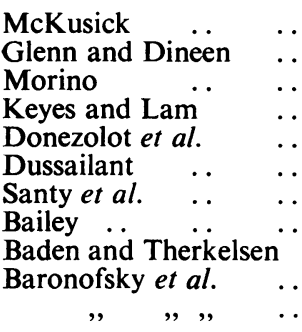 & $\begin{array}{l}37 \\
39 \\
28 \\
29 \\
29 \\
? \\
26 \\
41 \\
41 \\
43 \\
43\end{array}$ & $\begin{array}{l}\mathrm{M} \\
\mathbf{M} \\
\mathrm{M} \\
\mathrm{M} \\
\mathrm{M} \\
? \\
\mathrm{~F} \\
\mathrm{~F} \\
\mathrm{M} \\
\mathrm{F} \\
\mathrm{F}\end{array}$ & $\begin{array}{c}\text { Necropsy } \\
\text { Re-operation } \\
\text { ", } \\
\text { Necropsy } \\
\text { Re-operation } \\
\text {," } \\
\text {," }\end{array}$ & $\begin{array}{l}\text { True } \\
\text { True } \\
\text { True } \\
\text { True } \\
\text { True } \\
\text { True } \\
\text { True } \\
\text { False } \\
\text { False } \\
\text { False } \\
?\end{array}$ & $\begin{array}{l}\text { Rheumatic } \\
\text { Rheumatic } \\
\text { Rheumatic } \\
\text { No history of R.F. } \\
\text { Rheumatic } \\
\text { Rheumatic } \\
\text { ? cause } \\
\text { Calcified valve } \\
\text { Elastic valve } \\
\text { No details }\end{array}$ \\
\hline
\end{tabular}

\section{CASE REPORTS}

Case 1. E. S., a woman, aged 40, had severe disability, and a history of paroxysmal nocturnal dyspnœa. At operation she was found to have a moderately mobile valve; the circumference of the orifice was $4 \mathrm{~cm}$.; there was no calcification, but only a poor split was achieved. The final orifice had a circumference of $6 \mathrm{~cm}$. and there was no mitral regurgitation.

After the operation a fair result was recorded. She had one episode of congestive cardiac failure during the next 8 months, but her improvement was maintained. After this her condition deteriorated and she was readmitted two years after the original operation with as severe disability as she had had originally. At operation the valve was approached via the atrial wall as the appendage had been amputated at the first operation. Little restenosis had occurred, but slight incompetence was present. On this occasion the lateral commissure was completely split without an increase in the regurgitation.

When she was seen six months after her second operation, she was better than she had ever been, and was classed as a good result.

Case 2. T. T., a woman, aged 42 , had some years previously had a thyroidectomy for mitral stenosis; despite this she had severe disability and a history of recent congestive cardiac failure. At operation she was found to have a heavily calcified valve with a 4-cm. orifice. A minor degree of dilatation only was achieved.

For six months after this she enjoyed a slightly increased exercise tolerance, but then she returned to her original state and had repeated attacks of cardiac failure. She was readmitted four years after her operation for a second valvotomy. At operation the trans-atrial approach had to be used. The valve orifice was found to be $4.5 \mathrm{~cm}$. in circumference, this being a little less than at the end of the first operation. Efforts to increase the orifice by the usual methods failed. The method of trans-ventricular dilatation described by Logan (1955) was therefore used. By this means it was possible to rupture the calcified commissures, and the final circumference of the orifice was at least $8 \mathrm{~cm}$.

Immediately after the operation the signs of mitral stenosis had almost disappeared, and six months later her exercise tolerance was greatly improved, all signs of cardiac failure had gone, and she was classed as a good result. 
Case 3. F. M., a man, aged 40 , had a three-year history of increasing dyspnœa, and now had moderate disability. At operation heavy calcification was found along the lateral commissure, but the remainder of the valve was mobile. The orifice was $4 \mathrm{~cm}$. in circumference. The medial commissure was partially split leaving a poor opening. No impression could be made on the lateral commissure at this time.

He was somewhat better after his operation, but this improvement only lasted for six months. Thereafter he reverted to his pre-operative state, and later deteriorated still further. He was readmitted three years after the first operation. His disability was now severe, and he had functional tricuspid incompetence. At operation, the valve was approached via the atrial wall. He was found to have slight mitral incompetence, but otherwise the condition of the valve seemed identical with that described at the end of the first operation. On this occasion a full split of both commissures was achieved by the use of the dilator inserted through the ventricle; the blades were opened until they were $5 \mathrm{~cm}$. apart.

There was an immediate change in his physical signs and all those of mitral stenosis disappeared. When last seen his exercise tolerance was greatly improved and a good result was recorded.

Case 4. E. W., a woman, aged 39, had a two-year history of increasing dyspnœa, of repeated attacks of angina pectoris, and of paroxysmal nocturnal dyspnœa. Her disability was severe. At operation she was found to have a mobile valve with an orifice $3.5 \mathrm{~cm}$. in circumference. There was slight mitral regurgitation. The commissures were both heavily calcified and only a poor split was achieved, the final orifice being $5 \mathrm{~cm}$. in circumference.

There was some improvement in her exercise tolerance for four months, but after this she deteriorated gradually and on readmission 18 months after the first operation she was worse than she had ever been.

At operation the valve was approached through the atrial wall, the orifice was found to be $5 \mathrm{~cm}$. in circumference, and the regurgitation persisted unaltered. On this occasion the valve was successfully split using the transventricular route; the final circumference of the orifice was $8 \mathrm{~cm}$.

Four months later, she had improved considerably more than before; the diastolic murmur was short and quiet, and she was classed as a good result.

Case 5. R. R., a woman, aged 40, had had bronchitis and increasing dyspnœa for the last six years. On admission her disability was severe. At operation the appendage was found to be shrivelled up and the approach had therefore to be made via the atrial wall. The valve was mobile and elastic, there was no calcification, and the orifice had a circumference of $3 \mathrm{~cm}$. A poor split only was achieved.

For a month after her operation there was slight improvement of her exercise tolerance, but then she deteriorated to her condition before operation.

She was readmitted two years after her first operation and a second attempt was made via the atrial wall. Again she was found to have a tight stenosis with a valve orifice of $3.5 \mathrm{~cm}$. circumference. An attempt was made to split the commissures by the transventricular route, but despite wide opening of the dilator, the elastic property of the valve prevented a proper split: the final orifice was estimated as only $6 \mathrm{~cm}$. Very little improvement followed this operation and she now has severe cardiac failure again. She died from a cerebal embolas three months after a third operation.

Case 6. P. B., a woman, aged 36, had a moderate disability (Grade 2) and she was orthopnœic. At operation the valve was found to be mobile, a moderate degree of incompetence was present, and the stenosis was by no means tight $(5 \mathrm{~cm}$. circumference). Both defects were thought to be contributing to her disability. A partial split of the anterolateral commissure was done and the final orifice had a circumference of $6.5 \mathrm{~cm}$.

Her convalescence was prolonged and very little improvement was achieved by the operation. After one year she was as bad as ever. She was readmitted six months later with signs of considerable mitral stenosis, but of little incompetence. At operation the valve was approached via the atrial wall. The orifice had decreased little (circumference $5.5 \mathrm{~cm}$.) and as finger fracture was found to be impossible, a transventricular valvotomy was done. Both commissures were thus fully opened, but the dilator became caught in the chordæ and the incompetence was increased. Despite this the patient made a good recovery and when last seen her exercise tolerance was improved.

Case 7. I. B., a woman, aged 26, gave a history of increasing dyspnœa and was severely disabled (Grade 3). There was functional tricuspid incompetence. At operation the valve was approached via the atrial wall as the appendage had no lumen. Extensive loose clot was encountered in the atrial cavity. There was tight stenosis of the valve and it was heavily calcified. Little increase in the orifice was achieved on this occasion (final circumference $4 \mathrm{~cm}$. instead of $3 \mathrm{~cm}$.). After operation she had a cerebral embolus, from which she made a slow but almost complete recovery.

A surprising amount of improvement in the exercise tolerance was achieved by this inadequate operation, and she was classed as a good result for 18 months. After that she deteriorated and was readmitted one year later. By then her disability was as bad as ever and she had congestive cardiac failure. She had signs of tight mitral stenosis and of tricuspid incompetence.

At operation the valve was again approached via the atrial wall. The orifice was again found to be $3 \mathrm{~cm}$. in circumference but there was no incompetence. No impression could be made on the stenosed valve with a finger, but an almost complete split of both commissures was achieved via the ventricle $(9 \mathrm{~cm}$. circumference). Her exercise tolerance was improved. 
Case 8. M. E., a woman, aged 37, had severe disability (Grade 3) and she was orthopnœic. At operation she was found to have moderate stenosis, the valve being mobile and not calcified. Only a poor split was made, the postero-medial commissure being almost completely opened. The other commissure could not be split.

A fair degree of improvement only was achieved and this was maintained for 3 years. From then on she deteriorated and within three months she was as bad as ever. On readmission she had signs of tight stenosis but none of incompetence. At operation it was possible to approach the valve via the appendage again. A tight stenosis had recurred $(3.5 \mathrm{~cm}$. circumference) and as valvotomy by the usual means was found impossible, both commissures were fully opened by the transventricular route, the final orifice having a circumference of $10 \mathrm{~cm}$. She made a good recovery from her operation but some incompetence followed.

Case 9. A woman, aged 43, had a history of progressive dyspnœa for the last three years. Recently she had become gravely disabled with hæmoptyses and orthopnœa. At operation by Mr. Holmes Sellors she was found to have a soft mobile valve with a very tight stenosis: the lateral commissure was completely divided and the medial one for two-thirds of its length, and afterwards the diastolic murmur had almost disappeared.

After three months a fair result had been achieved, and her ankle odema had gone. Then she deteriorated and seven months after her operation was as bad as she had ever been and remained so until her readmission four years after her first operation in congestive cardiac failure that responded poorly to treatment. Cardiotomy was undertaken as an emergency. As the appendage had not been amputated at the first operation it was possible to approach the valve the usual way. There was a tight stenosis $(3.5 \mathrm{~cm}$. circumference) and slight mitral incompetence, but the valve was still freely mobile. On this occasion a complete split of both commissures was obtained by means of the finger and knife. A fair result was achieved by this operation but she has recently had another attack of congestive cardiac failure.

Case 10. A. A., a woman, aged 46, had had several attacks of pulmonary œedema during the past 18 months. She had moderate disability and gave a history of paroxysmal nocturnal dyspnœa and of orthopnœa. At operation she was found to have a mobile elastic valve but only a fair split was achieved: the medial commissure was completely divided but little impression could be made on the lateral one. The final orifice was about $6 \mathrm{~cm}$. in circumference.

A little improvement was achieved by this operation but it was not maintained. She was readmitted three years later. Her disability was the same as before and her physical signs were unaltered. At operation the valve was approached via the atrial wall, and was found to be soft and mobile with a circumference of $4.5 \mathrm{~cm}$. The medial commissure gave the impression of having completely refused. Again little improvement could be obtained with the finger or the knife. A dilator was therefore passed through the ventricular wall and opened widely. Both commissures were thus completely split, and the final circumference was thought to be $9 \mathrm{~cm}$. There has been considerable objective improvement since this operation.

Case 11. D. D., a woman, aged 38, had a history of occasional hæmoptyses and of recent ascites. Her disability was severe. At operation her appendage was found to be full of clot: this was dissected out and the valve was approached in the usual way. It was found to be mobile and tightly stenosed. The medial commissure was completely divided, but the lateral one was not split beyond the point of tendon insertion.

After the operation she had an excellent result with no disability whatever. This improvement was maintained for two and a half years. Dyspnœa then recurred, and she had several attacks of paroxysmal nocturnal dyspnœa. There was no history to suggest that she had had a recrudescence of rheumatic fever.

She was readmitted three years later with signs of tight mitral stenosis. Her disability was again severe. At operation it was possible to approach the valve by the usual route as the appendage had not been amputated. The mitral orifice was $4 \mathrm{~cm}$. in circumference and the medial commissure was completely refused. Only a moderate increase could be achieved with the finger and knife and the valve was therefore split completely via the ventricle. A minor degree of incompetence was created in the process. Little improvement was achieved at first, but afterwards she was improved.

Case 12. L. J., a woman, aged 39, had a six-year history of increasing dyspnœa, and of occasional ankle œdema. She was moderately disabled (Grade 2 ) and had a pure mitral stenosis. At operation, she was found to have a mobile mitral valve with a moderate degree of stenosis. The antero-lateral commissure was fully split; the postero-medial one was not divided as it was heavily calcified. A good result was achieved by this operation until three years later, when she had subacute bacterial endocarditis, the infecting organism being Staphylococcus aureus. She developed signs of right heart failure and of mitral incompetence, but recovered slowly with penicillin treatment, but after her discharge her exercise tolerance gradually decreased, and she was readmitted a year later with severe disability (Grade 3). She was diagnosed as restenosis. At operation the valve was approached via the atrial wall, and both commissures were found to be firmly fused with an orifice of $3.5 \mathrm{~cm}$. in circumference, but no incompetence. The antero-lateral commissure was easily split with the finger, but the methods of transventricular dilatation had to be used to open the postero-medial one. Grade 1 mitral incompetence was created but the patient made a good recovery and now has a good exercise tolerance. 
The first eight cases were examples of false restenosis in that the original division of the commissures was not carried beyond the critical point of tendon insertion on either side in any of them. The last four were examples of true restenosis as in all of them at least one commissure was fully divided. The salient features of these 12 cases are summarized in Table II.

TABLE II

Details of the Twelve Cases Reported Here

\begin{tabular}{|c|c|c|c|c|c|c|c|c|}
\hline \multirow[b]{2}{*}{ Case } & \multirow{2}{*}{$\begin{array}{c}\text { Age } \\
\text { and sex }\end{array}$} & \multirow[b]{2}{*}{ First operation } & \multirow{2}{*}{$\begin{array}{l}\text { Interval } \\
\text { in years }\end{array}$} & \multirow{2}{*}{$\begin{array}{l}\text { Type of } \\
\text { restenosis }\end{array}$} & \multirow{2}{*}{$\begin{array}{l}\text { Comment and } \\
\text { cause of inade- } \\
\text { quate operation }\end{array}$} & \multicolumn{3}{|c|}{ Second operation } \\
\hline & & & & & & Approach & $\begin{array}{c}\text { Com- } \\
\text { missurotomy * }\end{array}$ & Result \\
\hline $\begin{array}{r}1 \\
2 \\
3 \\
4 \\
5 \\
6 \\
7 \\
8 \\
9 \\
10 \\
11 \\
12\end{array}$ & $\begin{array}{ll}40 & \mathrm{~F} \\
42 & \mathrm{~F} \\
40 & \mathrm{M} \\
39 & \mathrm{~F} \\
40 & \mathrm{~F} \\
36 & \mathrm{~F} \\
26 & \mathrm{~F} \\
37 & \mathrm{~F} \\
43 & \mathrm{~F} \\
46 & \mathrm{~F} \\
38 & \mathrm{~F} \\
32 & \mathrm{~F}\end{array}$ & $\begin{array}{l}\text { Dil. } \\
\text { Half P.M.C. } \\
\text { Dil. Half P.M.C. } \\
\text { Dil. } \\
\text { Dil. } \\
\text { Half A.L.C. } \\
\text { Dil. } \\
\text { Dil. Half P.M.C. } \\
\text { Almost complete } \\
\text { One comm. } \\
\text { One comm. } \\
\text { One comm. }\end{array}$ & $\begin{array}{l}2 \\
4 \\
3 \\
11 \frac{1}{2} \\
2 \\
2 \\
2 \frac{1}{2} \\
3 \\
4 \\
3 \\
2 \frac{1}{2} \\
5\end{array}$ & $\begin{array}{l}\text { False } \\
\text { False } \\
\text { False } \\
\text { False } \\
\text { False } \\
\text { False } \\
\text { False } \\
\text { False } \\
\text { True } \\
\text { True } \\
\text { True } \\
\text { True }\end{array}$ & $\begin{array}{l}\text { Inexperience } \\
\text { Calcification } \\
\quad, \text {, } \\
\text { Elastic valve } \\
\text { M.I. and calcif. } \\
\text { Calcification } \\
\text { Elastic valve } \\
\text { No R.F. } \\
\text {," } \\
\text { S.B.E. }\end{array}$ & $\begin{array}{l}\text { W } \\
\text { W } \\
\text { W } \\
\text { W } \\
\text { W2 } \\
\text { W } \\
\text { W2 } \\
\text { A } \\
\text { A } \\
\text { W } \\
\text { A } \\
\text { W }\end{array}$ & $\begin{array}{l}\text { A.L.C. } \\
\text { Both comm. } \\
\text {," , } \\
\text { Dil." ," } \\
\text {," ," } \\
\text { Both comm. } \\
, ", \\
, ", \\
, ",\end{array}$ & $\begin{array}{l}\text { G } \\
G \\
G \\
G \\
P \dagger \\
F \\
G \\
G \\
F \\
F \\
G \\
G\end{array}$ \\
\hline
\end{tabular}

* At all the second operations division of the commissures was with a transventricular dilator except in Cases 1 and 9 when it was with finger and knife.

Cols. 3 and 8 . Dil.- dilatation only. One comm.-complete division of one commissure. P.M.C.-posteromedial commissure. A.L.C.- anterolateral commissure.

Col. 6. R.F.-rheumatic fever. S.B.E.-subacute bacterial endocarditis.

Col. 7. W refers to an approach through the atrial wall, W.2 to a second approach via this route, and A to an approach via the appendage.

Col. 9. G-good. F-fair. P-poor. †-died later.

\section{OPERATION FOR RESTENOSIS}

In nine of the twelve cases presented here, the approach was made through the atrial wall. The reason for this was that the appendage was removed at the first operation in the hope that the risk of late embolism might be lessened (Belcher and Somerville, 1955). In two of the nine, the valve was reached via the atrial wall at both operations, and in one a third approach has now been made by this route. Although this approach may be more difficult, it carries no added risk unless there is thrombus in the atrium. In these cases, only one ring of purse-string suture was used: the second row recommended by Baden and Therkelsen (1954) was found to be unnecessary. A small incision was made inside this ring and the opening was enlarged by the insertion of the finger. This avoided the risk of cutting the purse string suture. No trouble was met when the suture was tied, and in several cases no further stitch was needed in the atrial wall. In the other three the lumen of the atrium was reached via the appendage in the usual way, as it had not been amputated at the first operation (Table II).

In two of the twelve cases it was possible to divide the commissures in the normal way with finger and knife. In one of these true restenosis had occurred (Case 9); in the other the original valvotomy had been inadequate because of inexperience, and it was more successful on the second occasion (Case 1). In the remaining ten the commissure could not be divided by the normal method. In six of these (Cases 2, 3, 4, 6, 7, and 12) heavy calcification of the valve had prevented adequate splitting at the first operation. In two (Cases 5 and 8 ) the elasticity of the valve accounted for the poor split, and in the two where true restenosis had occurred (Cases 10 and 11) division of the commissure which was not cut at the first operation was again found to be impossible.

To achieve a complete division of the commissures in these ten patients the alternative method of transventricular dilatation described by Logan was used. When the valve had been explored a 
small incision was made in the wall of the left ventricle near the apex. A sound was passed into the lumen; this was withdrawn and the dilator was introduced; this was passed on until it could be felt engaging the orifice and it was then opened until the blades were $4 \mathrm{~cm}$. apart: the guard was then removed and the blades were further opened to $5 \mathrm{~cm}$. The dilator was then removed and the wound in the ventricle was easily controlled with a few sutures. In all save one case complete separation of both commissures was thus achieved.

TABLE III

Details of the Second Operations Reported by Others

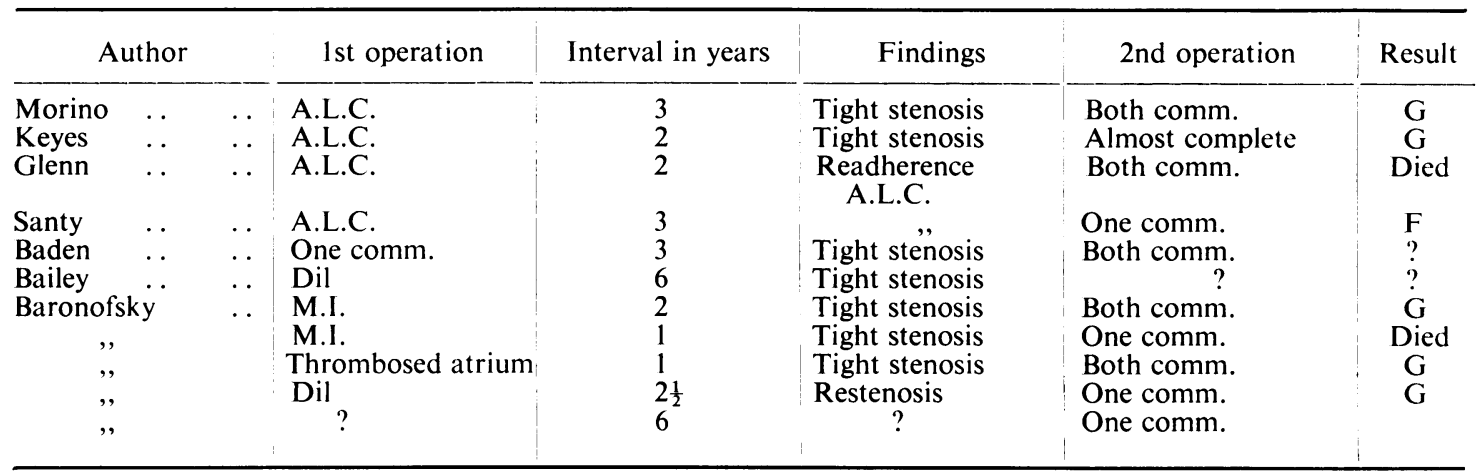

The abbreviations are the same as those in Table II.

\section{RESULTS}

There was no operative mortality, but a massive cerebral embolus caused one late death (Case 5). Of the others, eight have been classed as good and three as fair. Minor mitral imcompetence was created in Cases 6, 9, and 12 and considerably increased in Case 7 . In only eight of the twelve has a sufficient time elapsed to assess the extent of improvement. These results are perhaps not as good as might have been expected from the efficacy of the division of the commissures, all of which were good, but it is possible that further improvement will occur.

\section{Discussion}

Eleven of the twelve cases reported here are derived from a series of 240 operations, 120 of which were performed more than two years ago. They were classed as good where both commissures were fully opened, as fair to good where the split was almost complete; as fair where only one commissure was opened or where both were partially split, and as poor where neither commissure was divided beyond the critical point of tendon insertion.

The efficacy of the split had a close relationship to the incidence of restenosis. There were 186 patients in the first two groups; if restenosis had occurred in any of these it would have been true restenosis, but none of them has so far required a second operation. Of the 43 patients in whom the split was classified as fair, five have so far been operated on for a second time; two of these were regarded as true restenosis. Of the eleven in whom the split was regarded as poor, one died at operation, one has died since, and six have been operated upon for a second time: these were all examples of false restenosis.

These findings suggest that many patients who have a poor division of the commissures will almost certainly require a second operation, whereas those who have complete or almost complete division have only a small risk of restenosis.

These findings also re-emphasize the importance of adequate division of the commissures at the first operation, for it is probable that at least four of the twelve patients presented here would 
not have required a second operation if the transventricular dilator had been used on the first occasion when the knife and finger method failed.

The results in this series has shown that the second operation has been well worth while. The reported cases where a second operation has been done are summarized in Table III. As will be seen there are eleven cases in all; of these two died, but in the remainder the extent of improvement again followed the extent of the division closely.

It therefore seems that there is every justification for a second operation when restenosis is diagnosed, particularly in those patients in whom the original operation is known to have been inadequate. If false restenosis can be eliminated by a good division of the commissures at the first operation, restenosis will prove to be uncommon.

\section{Summary}

Two varieties of restenosis have been described; true restenosis, which occurs after one or both commissures have been fully split, and false restenosis where the original operation was inadequate. True restenosis may be rheumatic in origin; false restenosis may be inevitable after any poor commissurotomy.

The reported cases of restenosis have been reviewed, and twelve patients who have been operated upon for a second time are described. Eight had false restenosis and four had true restenosis.

There was no mortality in the series. The results have been satisfactory. In ten the second division of the commissures was performed by the transventricular technique of Logan. In all save three the approach was made through the atrial wall.

My thanks are due to Dr. D. E. Bedford and to Dr. K. Shirley Smith, under whose care some of these cases were admitted.

\section{REFERENCES}

Baden, H., and Therkelsen, F. (1954). Thorax, 9, 340.

Bailey, C. P. (1955). Surgery of the Heart. Kimpton.

Baker, C., Brock, R. C., and Campbell, M. (1955). Brit. med. J., 2, 983.

Baronofsky, I. D., Borden, C., Smith, R. F., and Sparafka, J. L. (1955). Ann. Surg., 142, 32.

Belcher, J. R., and Somerville, W. (1955). Lancet, 2, 1000.

Brock, R. C. (1952). Brit. Heart J., 14, 489.

(1956). Ann. Roy. Coll. Surg., 19, 1.

Canigia, A. (1955). Acta. Cardiol. (Brux.), 10, 67.

Cooley, D. A. (1951). Angiology, 2, 591.

Dussailant, G. (1954). Rev. Med. Chile, 82, 92.

Donzelot, E., Dubost, C., de Balzac, R. H., Métianu, C., and Guillemot, R. (1953). Arch. Mal. Coeur, 46, 300.

Glenn, F., and Dineen, P. (1956). Ann. Surg., 143, 405.

Glover, R. P., Davilla, J. C., O’Neill, J. E., and Janton, O. H. (1955). Circulation, $11,1$. (1955). Trans. Amer. Coll. Card., 5, 209.

Goodwin, J. F., Hunter, J. D., Cleland, W. P., Davies, L. G., and Steiner, R. E. (1955). Brit. med. J., 2, 573.

Jordan, P., and Hellems, A. K. (1952). Surg. Gyn. Obst., 95, 689.

Keyes, J. W., and Lam, C. R. (1954). J. Amer. med. Ass., 155, 247.

Lam, C. R. (1955). Cardiovascular Surgery. Saunders.

Logan, A. (1955). Personal communication.

McKusick, V. A. (1955). Arch. intern. Med., 95, 557.

Morino, F. (1955). Minerva Med. Tor., 46, 1033.

Muller, W. H. (1952). Surgery, 31, 602.

Santy, P., Froment, R., Gallavardin, L., Tolot, F. (1954). Arch. Mal. Cour, $47,7$.

Sellors, T. H., Bedford, D. E., and Somerville, W. (1953). Brit. med. J., 2, 1059.

Turner, H. W. D., and Fraser, H. R. L. (1956). Lancet, 2, 525.

Wood, P. (1954). Brit. med. J., 1, 1113.

(1956). Personal communication. 